Research Article

\title{
Modified Mathematical Model For Neutralization System In Stirred Tank Reactor
}

\author{
Ahmmed Saadi Ibrehem * \\ Department Chemical and Petroleum Engineering, UCSI-University, 56000 Kuala Lumpur, \\ MALAYSIA
}

Received: 1st March 2011; Revised: 28th March 2011; Accepted: 7th April 2011

\begin{abstract}
A modified model for the neutralization process of Stirred Tank Reactors (CSTR) reactor is presented in this study. The model accounts for the effect of strong acid [HCL] flowrate and strong base [NaOH] flowrate with the ionic concentrations of $[\mathrm{Cl}-]$ and $\left[\mathrm{Na}^{+}\right]$on the $\mathrm{Ph}$ of the system. In this work, the effect of important reactor parameters such as ionic concentrations and acid and base flowrates on the dynamic behavior of the CSTR is investigated and the behavior of mathematical model is compared with the reported models for the McAvoy model and Jutila model. Moreover, the results of the model are compared with the experimental data in terms of $\mathrm{pH}$ dynamic study. A good agreement is observed between our model prediction and the actual plant data. (C) 2011 BCREC UNDIP. All rights reserved
\end{abstract}

Keywords: Stirred Tank Reactors, Neutralization, Mathematical model, Dynamic studies

\section{Introduction}

A rigorous and generally applicable method of deriving dynamic equations for $\mathrm{pH}$ neutralization in Continuous Stirred Tank Reactors (CSTRs) was presented by McAvoy et al. ( 1972). The research work done by McAvoy was essential to the development of the fundamental modelling approach of the $\mathrm{pH}$ neutralization process in CSTRs. As cited and described in other literature, the use of the CSTR in developing the $\mathrm{pH}$ neutralization model was started over 50 years ago by Kramer (1956) and by Geerlings (1957). However those early studies concentrated largely on the dynamic behaviour of the $\mathrm{pH}$ electrode system. Subsequently, two crucial points in developing a $\mathrm{pH}$ neutralization process model which describes the nonlinearity of the neutralization process have emerged from published research. The two points are as follows:- i. Material balances in terms of hydrogen ion or hydroxyl ion concentrations would be extremely difficult to write down. This is due to the fact that the dissociation of water and resultant slight change in water concentration would have to be accounted. ii. Instead, material balances are performed on all other atomic species and all additional equilibrium relationships are used. The electroneutrality principle is used to simplify the equations.

Jutila \& Orava (1981) studied control and estimation Algorithms for Physico-Chemical model of pH-pocesses in Stirred Tank Reactors (CSTR). Gustafsson (1982) and Gustafsson \& Waller (1983) studied a reinforced McAvoy's modelling principles for $\mathrm{pH}$ neutralization processes and emphasised the fact that mass balances on the invariant species are inherently independent of reaction rates. As described in this paper, the "invariant

\footnotetext{
* Corresponding Author.

E-mail address: ahmadsaadi1@yahoo.com (A.S. Ibrehem)

Telp.: Tel: +60149360913
} 
species" is actually the species that remain chemically unchanged by the governing of reactions in the neutralization process whereas the "variant species" are the species that change in the neutralization process, such as the hydrogen ions.

Another interesting and widely used account of work involving the modelling of a $\mathrm{pH}$ neutralization process is by Wright \& Kravaris (1991). Their work provided a new approach of the design of nonlinear controllers for $\mathrm{pH}$ processes by defining an alternative equivalent control objective. That new approach results in a control problem that is linear. A minimal order model was produced by assuming that the flowrate of the titrant required to operate the reactor was negligible in comparison with the flow rate of the process streams.Abdul Aziz Ishak et al. (2001) study of the dynamics and control of a semibatch wastewater neutralization process in modeling and simulation is presented. Zainal Ahmad \& Fairuoze Roslin (2007) provide modeling of real $\mathrm{pH}$ neutralization process using multiple neural networks (MNN) combination technique. Rosdiazli Ibrahim (2008) provide an adequate dynamic nonlinear $\mathrm{pH}$ neutralization model, based on physical and chemical principles that can represent the real $\mathrm{pH}$ neutralization plant.

Mathematical models of chemical systems were developed for many reasons. Thus, they may be constructed to assist in the interpretation of experimental data, to predict the consequence of changes of system input or operating conditions, to deduce optimal system or operating conditions and for control purposes. Usually there is an interest for dynamic model made to design and/or test the proposed control system. The dynamic and steady state simulation model for $\mathrm{pH}$ neutralization process consists of a system of equations based on mass and charge balances on the continuous stirred tank reactor (CSTR).

\section{Materials and Methods}

The process can be considered as a continuous stirred tank reactor (CSTR) to neutralize a strong acid with a strong base manipulated by a control valve. The process consists of an influent stream $(\mathrm{HCl})$, reagent stream $(\mathrm{NaOH})$ to regulate the $\mathrm{pH}$ of the effluent stream, and an effluent stream. A schematic diagram is shown in Figure (1). The data of this reaction was taken from a previous experimental work by Ai-Poh Loh (2006).

\subsection{Assumption for the Present Model}

A dynamic model of the process is obtained from the component material balance and the

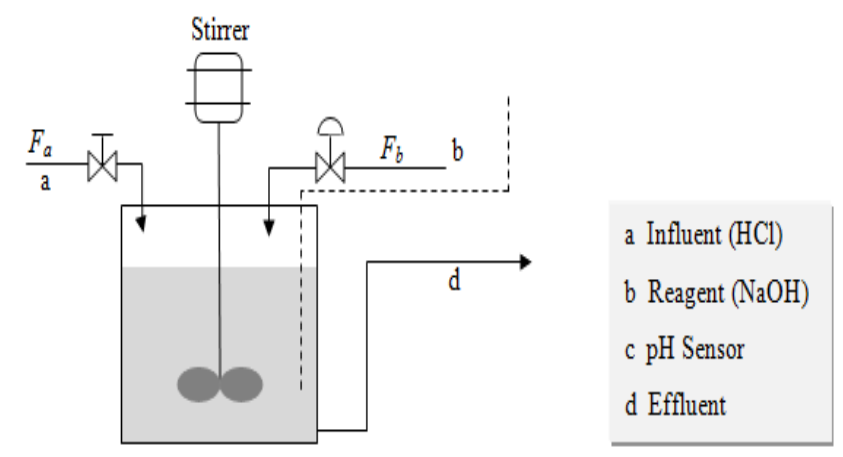

Figure 1. Schematic of a $\mathrm{pH}$ neutralization process

equilibrium relationship under the following assumptions:

(1) The acid-base reactions are ionic and can be considered to take place, with the result that the rate of reaction can be considered. The stirred tank process dynamics in this case would thus be not similar to the case of mixing or blending non reacting streams.

(2) The system is in an ideal condition without any pollutant influence.

(3) Constant temperature of 25 0C. $\mathrm{pH}$ electrode potential is temperature dependent and this should be accounted for with high temperature applications.

(4) Perfect mixing.

(5) No valve dynamics. Usually, the valve dynamics are much faster than the process dynamics and, thus, can be ignored.

(6) $\mathrm{pH}$ probe dynamics can be significant and are often represented by a first order lag.

(7) The volume of the reacting mixture in the tank is constant and equal to $\mathrm{V}$.

The basic model is considered adequate for this case study since it represents the dominant nonlinear characteristics of this single acid-single base continuous stirred tank reactor (CSTR) process.

\subsection{Model for Strong Acid-Strong Base System}

Consider a stirred tank into which hydrochloric acid of concentration [ $\mathrm{HCl}]$ flows into the tank at a rate $\mathrm{Fa}$ (influent stream) and is neutralized by sodium hydroxide of concentration $[\mathrm{NaOH}]$ flows at a rate $\mathrm{F}_{\mathrm{b}}$ (reagent).

The chemical reaction of these two solutions occurring in the stirred tank reactor is : 
$\mathrm{NaOH}+\mathrm{HCL}+\mathrm{H}_{2} \mathrm{O} \rightarrow \mathrm{H}_{2} \mathrm{O}+\mathrm{CL}^{-1}+\mathrm{Na}^{+}+\mathrm{H}^{+}+$ $\mathrm{OH}^{-}$

Thus, the ionic concentrations of [Cl-] and [Na+] in the outflow from the tank would be related to the total flows $\mathrm{Fa}, \mathrm{Fb}$ and to the feed concentrations of strong acid $[\mathrm{HCl}]$ and strong base $[\mathrm{NaOH}]$ entering the tank. Rate constant $\mathbb{G L}_{\mathrm{H}}$ reaction ( k1 ) (Perry's book, 1997).Hence, the masst balances on $\mathrm{NaOH}$ and Sodium ion.

$$
\begin{aligned}
& \mathrm{Cb}=[\mathrm{NaOH}] \\
& \frac{d\left[C_{b}\right]}{d t}=\frac{1}{v}\left\{C_{b} F_{b}-\left(F_{a}+F_{b}\right) C_{b}\right\}-k_{1} C_{b} C_{a} \\
& \frac{d\left[N a^{*}\right]}{d t}=\frac{1}{V}\left\{-N a+\left(F_{a}+F_{b}\right)\right\}+k_{1} C_{a} C_{\bar{b}}
\end{aligned}
$$

Mass balance on $\mathrm{HCl}$ and Chloride ion

$$
\mathrm{Ca}=[\mathrm{HCl}]
$$

$$
\begin{aligned}
& \frac{d\left[C_{a}\right]}{d t}=\frac{1}{v}\left\{C_{a} F_{a}-\left(F_{a}+F_{b}\right) C_{a}\right\}-k_{1} C_{b} C_{a} \\
& \frac{d\left[C l^{-}\right]}{d t}=\frac{1}{v}\left\{-C l^{-}\left(F_{a}+F_{b}\right)\right]+k_{1} C_{a} C_{b}
\end{aligned}
$$

Acids and bases have free hydrogen and hydroxyl ions, respectively. Since the relationship between hydrogen ions and hydroxide ions in a given solution is constant for a given set of conditions, either one can be determined by knowing the other.

$$
\begin{gathered}
{\left[\mathrm{H}^{+}\right]\left[\mathrm{OH}^{-}\right]=K_{w}=10^{-14}} \\
{\left[\mathrm{OH}^{-}\right]=\frac{K_{w}}{\left[H^{+}\right]}}
\end{gathered}
$$

Taking the derivative of equation (6):

$$
\frac{d\left[O H^{-}\right]}{d t}=\frac{d}{d t}\left(\frac{K_{w}}{\left[H^{+}\right]}\right)=-\frac{K_{w}}{\left[H^{+}\right]^{2}} \frac{d\left[H^{+}\right]}{d t}
$$

Electroneutrality balance

$$
\left[\mathrm{H}^{+}\right]+\left[\mathrm{Na}^{+}\right]=\left[\mathrm{Cl}^{-}\right]+\left[\mathrm{OH}^{-}\right]
$$

Rearranging equation (8) as:

$$
\left[\mathrm{H}^{+}\right]-\left[\mathrm{OH}^{-}\right]=\left[\mathrm{Cl}^{-}\right]-\left[\mathrm{Na}^{+}\right]
$$

Taking the derivative of equation (9):

$$
\frac{d\left[\mathrm{H}^{+}\right]}{d t}-\frac{d\left[\mathrm{OH}^{-}\right]}{d t}=\frac{\mathrm{d}\left[\mathrm{Cl}^{-}\right]}{\mathrm{dt}}-\frac{d\left[\mathrm{Na}^{+}\right]}{d t}
$$

$=\left(\frac{\left(H^{+}\right)^{2}}{\left(H^{+}\right)^{2}+K_{W}}\right)\left[\frac{1}{V}\left\{-C l^{-}\left(F_{a}+F_{b}\right)\right]+K_{1} C_{a} C_{b}-\frac{1}{V}\left\{-N q^{+}\left(F_{a}+\right.\right.\right.$

Substituting [OH-] from the equation (7) into (10) yields:

$$
\begin{aligned}
& \frac{d\left[\mathrm{H}^{+}\right]}{d t}+\frac{K_{w}}{\left[\mathrm{H}^{+}\right]^{2}} \frac{d\left[\mathrm{H}^{+}\right]}{d t}=\frac{\mathrm{d}\left[\mathrm{Cl}^{-}\right]}{\mathrm{dt}}-\frac{d\left[\mathrm{Na}^{+}\right]}{d t} \\
& \frac{d\left[\mathrm{H}^{+}\right]}{d t}\left(\frac{\left[\mathrm{H}^{+}\right]^{2}+K_{w}}{\left[\mathrm{H}^{+}\right]^{2}}\right)=\frac{\mathrm{d}\left[\mathrm{Cl}^{-}\right]}{\mathrm{dt}}-\frac{d\left[\mathrm{Na}^{+}\right]}{d t}
\end{aligned}
$$

Substituting of equations (2) and (4) into equation (12) gives:

$$
\begin{array}{r}
-\frac{+2}{+2+}[-\{-(+)\}+1 \\
\left.-\frac{1}{-}\{-+(+)\}+1\right]
\end{array}
$$

We can rearrange last equation as follows;

$$
\frac{d H}{d t}=\frac{1}{V}\left(\frac{\left(H^{+}\right)^{2}}{\left(H^{+} \eta^{2}+R_{W}\right.}\right)\left(F_{a}+F_{b}\right)\left[N a^{+}-C l^{-}\right]
$$

After rearranging;

Substituting [OH-] from the equation (8) into (14) yields:

$$
\frac{d H}{d t}=\frac{1}{V}\left(\frac{\left(H^{+}\right)^{2}}{\left(H^{+}\right)^{2}+K_{W}}\right)\left(F_{a}+F_{b}\right)\left[O H^{-}-H^{+}\right]
$$

Equation (15) can be solved numerically for $\left[\mathrm{H}^{+}\right]$, while the $\mathrm{pH}$ is a logarithmic function; a change of one $\mathrm{pH}$ unit represents a ten-fold change in hydrogen ion concentration:

$$
\mathrm{pH}=-\log \left[\mathrm{H}^{+}\right]
$$

\section{Model solution and analysis}

The previously described process model equations (1-16) incorporating the parameter values of Table (1) were solved in Matlab using the 
Table 1. Estimation of the reactor model parameters for mathematical model system

\begin{tabular}{ll}
\hline \multicolumn{1}{c}{ Symbol } & \multicolumn{1}{c}{ Value and Unit } \\
\hline $\mathrm{C}_{\mathrm{a}}$ & $0.000001 \mathrm{~mol} / \mathrm{liter}$ \\
$\mathrm{C}_{\mathrm{b}}$ & $0.000001 \mathrm{~mol} / \mathrm{liter}$ \\
$\mathrm{F}_{\mathrm{a}}$ & $0.016667 \mathrm{liter} / \mathrm{s}$ \\
$\mathrm{F}_{\mathrm{b}}$ & $0.016667 \mathrm{liter} / \mathrm{s}$ \\
$\mathrm{K}_{\mathrm{w}}$ & $10^{-14}$ \\
$\mathrm{~V}$ & 30 liter \\
$\mathrm{k}_{1}$ & $0.001 \mathrm{sec}^{-1}$ \\
Temperature & $25{ }^{\circ} \mathrm{C}$ \\
Pressure & $1 \mathrm{~atm}$ \\
\hline
\end{tabular}

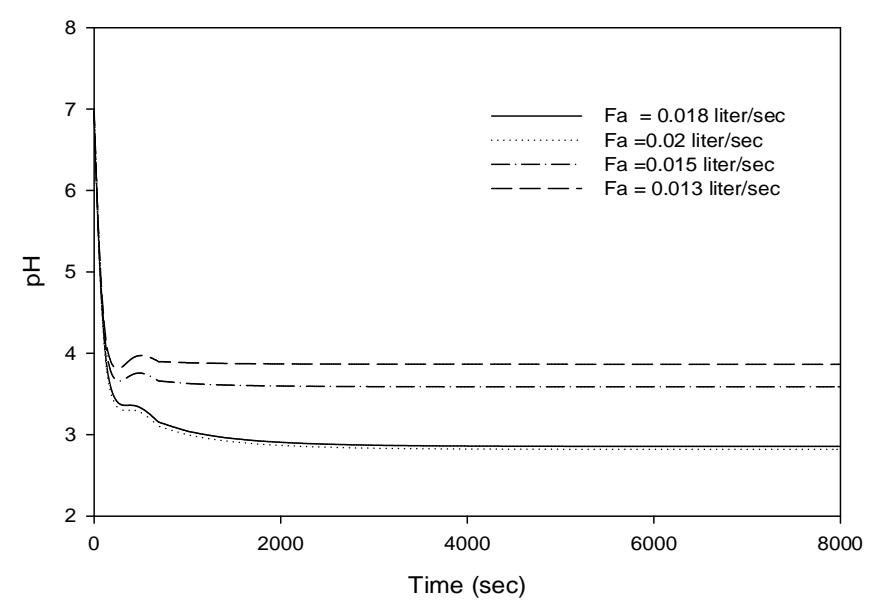

Figure 2. Effects of acid flowrate in the $\mathrm{pH}$ with variable time

Differential Algebraic Equation solver (DAE) with the fourth order Runge-kutta method. Physical constants and operating parameters for the mathematical model system were used in Table (1). The process was simulated for the effects of $[\mathrm{NaOH}],[\mathrm{HCl}],\left[\mathrm{Na}^{+}\right]$and $[\mathrm{Cl}-]$ on $\mathrm{pH}$ with variable time.

In the following sections the simulation results are described for the different concentrations of the system. Figure (2) shows the effect of [HCl] flow rate on the $\mathrm{pH}$ of the system. The $\mathrm{pH}$ profile has an inverse relationship with the increase in flow rate of $[\mathrm{HCl}]$. Figure (3) shows the effect of $[\mathrm{NaOH}]$ flow rate on the $\mathrm{pH}$ of the system. The $\mathrm{pH}$ profile has an proporational relationship with the increase in flow rate of $[\mathrm{NaOH}]$.

Figures (4) and (5) show the effect of concentrations $[\mathrm{Cl}-]$ and $\left[\mathrm{Na}^{+}\right]$on the $\mathrm{pH}$ with respect to time. It can be seen that the $\mathrm{pH}$ depends on the concentrations $\left[\mathrm{Cl}^{-}\right]$and $\left[\mathrm{Na}^{+}\right]$. The $\mathrm{pH}$ has

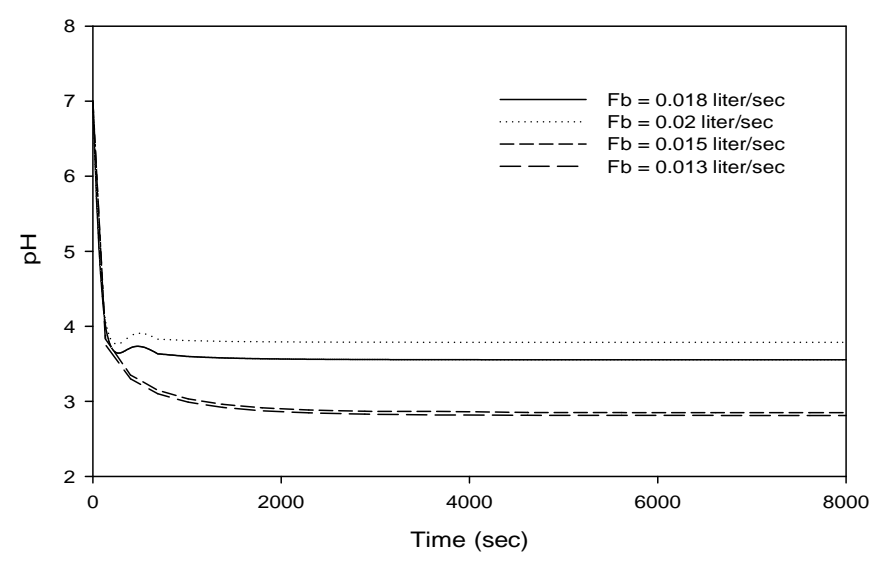

Figure 3. Effects of base flowrate in the $\mathrm{pH}$ with variable time

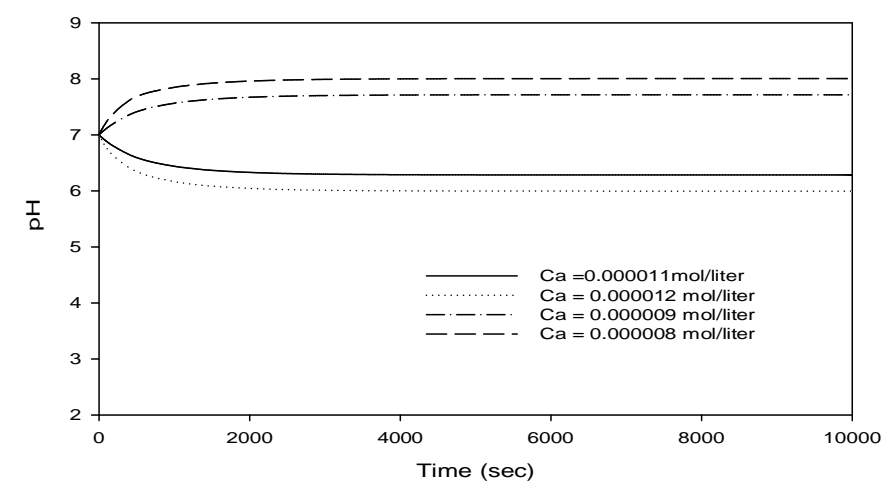

Figure 4. Effects of concentation of [Cl-] in the $\mathrm{pH}$ with variable time

an inverse relationship with the increase in concentrations [Cl-] as shown in Figure (4). The $\mathrm{pH}$ has proporational relationship with the increase in concentrations $\left[\mathrm{Na}^{+}\right]$as shown in Figure (5). All these behavior are mention above can be represented in Figures (4) and (5) respectively.

\section{Model validation with previous models and experimental data}

Comparison of the two previously available models; McAvoy model and Jutila model and modified model in terms of their dynamic predications is shown in Figures (6),(7),(8) and (9). The figures indicates that the predications of the three models are close to each other at the startup conditions of the reactor operation. System works at nominal condition as in Table (1) then at time $3000 \mathrm{sec}$ increases acid flowrate to $10 \%$ and makes comparison between experimental results of number 1 versus model predicted $\mathrm{pH}$ and two 


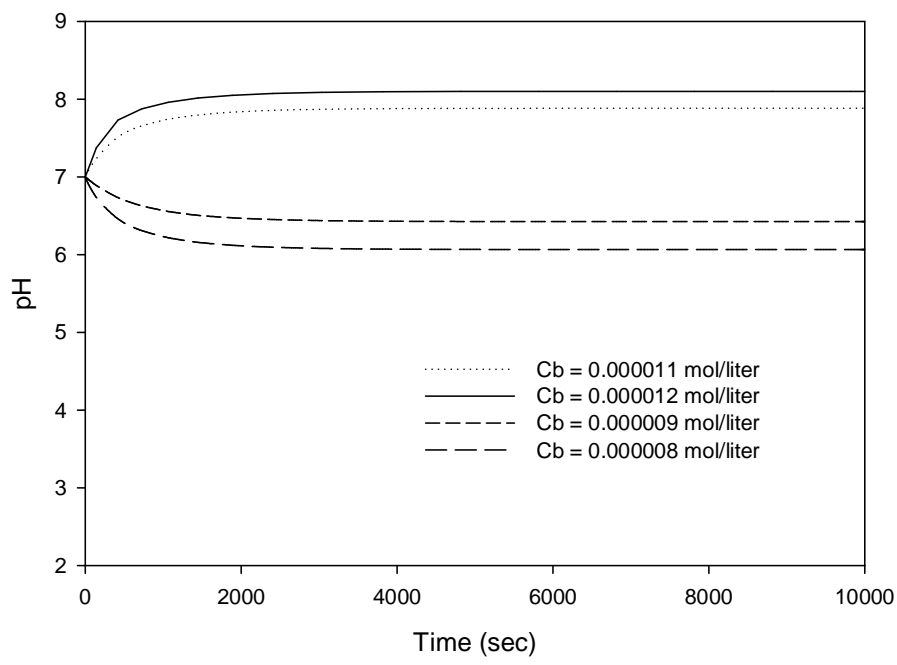

Figure 5. Effects of concentation of $[\mathrm{Na}+]$ in the $\mathrm{pH}$ with variable time

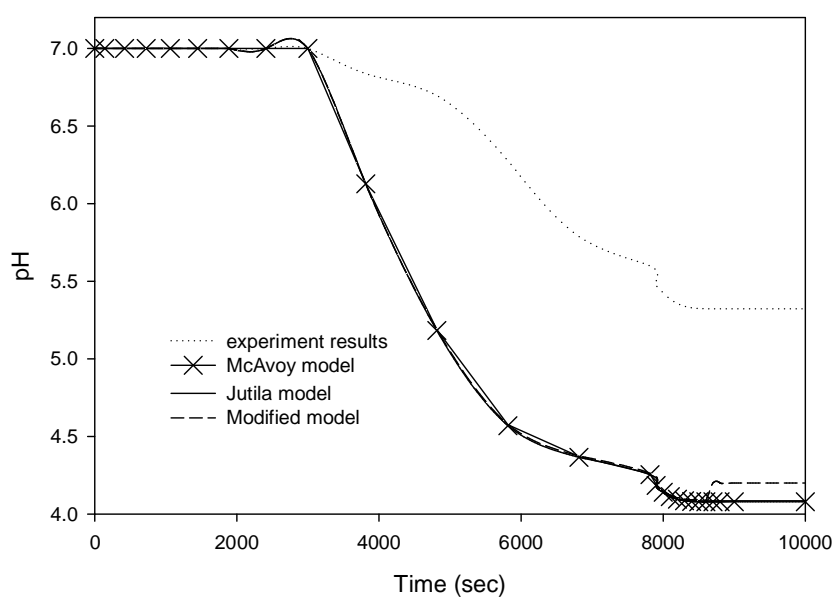

Figure 6. Experimental results versus model predicted $\mathrm{pH}$ using $+10 \%$ a step change of the acid flow rate in the system

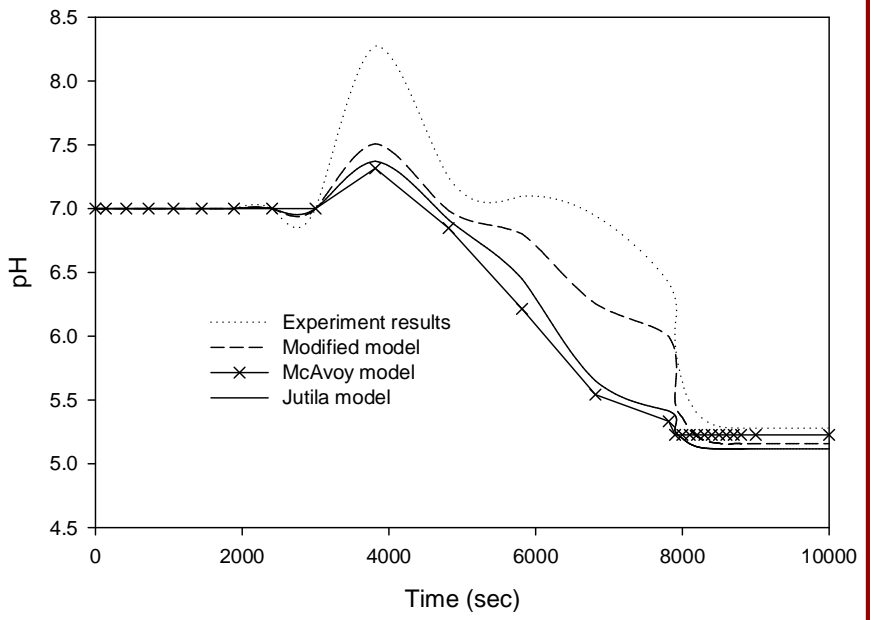

Figure 7. Experimental results versus model predicted $\mathrm{pH}$ using $-10 \%$ a step change of the acid flow rate in the system

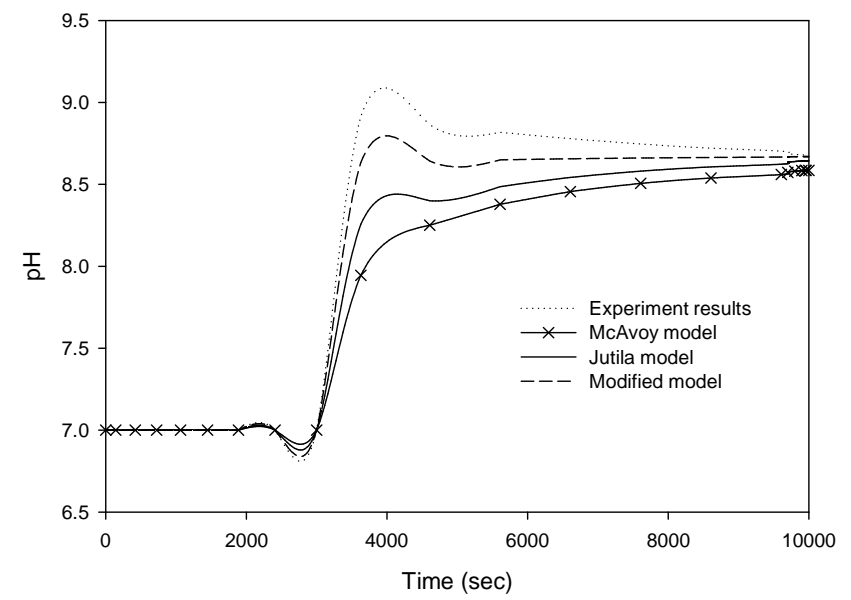

Figure 8. Experimental results versus model predicted $\mathrm{pH}$ using $+10 \%$ a step change of the base flow rate in the system

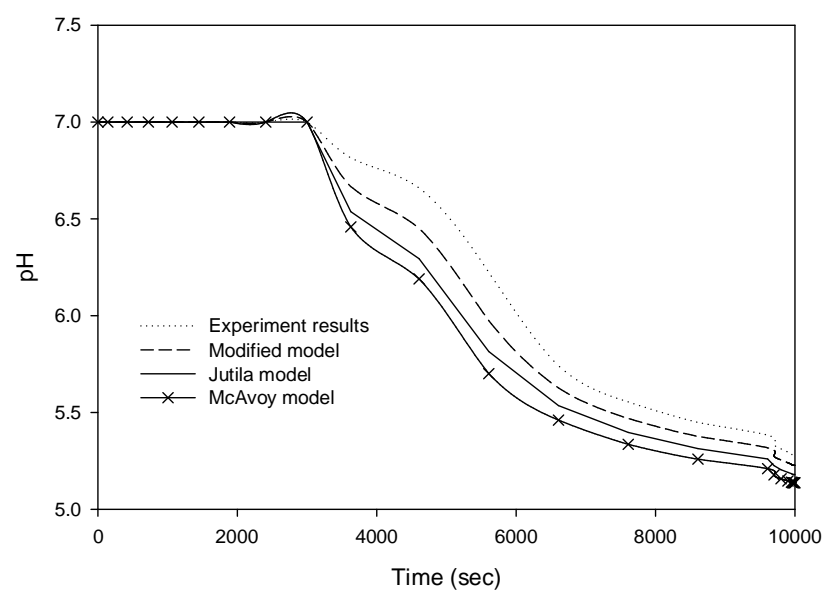

Figure 9. Experimental results versus model predicted $\mathrm{pH}$ using - $10 \%$ a step change of the base flow rate in the system 
previous models as shown in Figure (6). Experiment number 2 the system works at nominal conditions then at time $3000 \mathrm{~s}$ decreases acid flowrate to $10 \%$ and makes comparison between experimental results versus model predicted $\mathrm{pH}$ and two previous models as shown in Figure (7).

In experiment 3 the system works at nominal conditions then at time $3000 \mathrm{~s}$ increases base flowrate to $10 \%$ and makes comparison between experimental results versus model predicted $\mathrm{pH}$ and two previous models as shown in Figure (8). In experiment 4 the system works at nominal conditions then at time $3000 \mathrm{~s}$ decreases base flowrate to $10 \%$ and makes comparison between experimental results versus model predicted $\mathrm{pH}$ and two previous models as shown in Figure (9).

However this behavior changes as the process dynamics proceeds in time and by the end of the time of reaction, the modified model becomes closer to Jutila model and McAvoy model. The close behavior of modified mathematical model to the Jutila model is mainly due to the fact that the same consideration for the rate reaction about concentrations of ions happens in the process.

In summary the dynamic behavior of the modified model is very close to Jutila model and McAvoy model in the initial stages and starts to differ with change in the time. The accuracy of the dynamic behavior of these models can be seen from their comparison with actual experimental data [Loh et al., 2001] as shown in Figures (6),(7),(8) and (9).

\section{Conclusion}

A modified dynamic structure model was developed in this work. This model takes into account the presence of acid and bases in the reaction with ions which depend on chemical reactions of acid and bases concentrations feeds. In addition, the concentrations effect of acid and bases on the system were included. Model simulations indicate that it is capable of predicating reactor performance indicators as well as calculating the changes of ions through chemical of the reaction. The model presented in this work was compared with two previously available models and results of the proposed model were compared with experimental data of neutralization process. From its observed accuracy, we can conveniently use this model as a predictive tool to study the effects of operating, kinetic and hydrodynamics parameters on the reactor performance. The comparison results between the modified model and the other two available models gave good indication about the behavior of the present model which is very close to that of the McAvoy model and Jutila model in the initial stages but little different with change in time. The model developed here will also be used in modelbased prediction control to control the reactor which is part of our future work.

\section{References}

[1] Ai-Poh Loh,, Dhruba Sankar De, and P. R. Krishnaswamy, ñpH and Level Controller for a $\mathrm{pH}$ Neutralization Processò, Ind. Eng. Chem. Res., 2001, 40 (16), pp $3579 і ̈ 3584$.

[2] Jutila, P. \& Orava, J. P. 1981, "Control and Estimation Algorithms for Physico-Chemical Models of pH-Processes in Stirred Tank Reactors", Int. Journal of Sys. Sci., vol. 12, no. 7 , pp. 855-875.

[3] McAvoy, T. J., Hsu, E., \& Lowenthals, S. 1972, "Dynamics of $\mathrm{pH}$ in controlled stirred tank reactor", Ind Eng Chem Process Des Develop, vol. 11, no. 1, pp. 68-78.

[4] Rosdiazli Ibrahim "Practical Modelling And Controlimplementation Studies On A pH Neutralization Process Pilot Plant", PhD Thesis, 2008

[5] Waller, K. V. \& Gustafsson, T. K. 1983, "Fundamental Properties of Continuous $\mathrm{pH}$ Control", ISA Transactions, vol. 22, no. 1, pp. 25-34.

[6] Wright, R. A. \& Kravaris, C. 1991, "Nonlinear control of $\mathrm{pH}$ processes using the strong acid equivalent", ", Ind. Eng. Chem. Res., vol. 30, no.7, pp. 1561-1572.

[7] Robert H.Perry , "Perry's Chemical Engineering Handbook", 1997.

[8] Zainal Ahmad and Fairuoze Roslin, "Modeling of real $\mathrm{pH}$ Neutralization Process using Multiple Neural Networks (MNN) Combination Technique", International Conference on Control, Instrumentation and Mechatronics Engineering (CIM'07), Johor Bahru, Johor, Malaysia, May 28-29,2007. 